TAO, Vol. 11, No. 3, 689-700, September 2000

\title{
Phenomena Associated with the 1999 Chi-Chi Earthquake in Taiwan, Possible Precursors and After Effects
}

\author{
Allen T. Chen ${ }^{1}{ }^{*}$, Toru Ouchi ${ }^{2}$, Aiming Lin $^{3}$, Jacy Chen ${ }^{1}$ and Tadashi Maruyama ${ }^{3}$ \\ (Manuscript received 31 March 2000, in final form 31 May 2000)
}

\begin{abstract}
The authors conducted interviews about the Chi-Chi earthquake during a geological field investigation in order to build records about its possible precursors and after effects for future preservation. The precursors reported include aberrant animal behavior and non-animal related activity. Phenomena observed during and after the earthquake may be related to seismic energy released and displacement of the crustal structure. We, therefore, suggest establishing a warning system based on a watch network under proper government jurisdiction. Such a warning system would be beneficial in the prevention of future prevent casualties.
\end{abstract}

(Key words: Chi-Chi earthquake, Precursor, Chelungpu fault)

\section{INTRODUCTION}

The Chi-Chi earthquake $\left(M_{L}=7.3\right.$ ) occurred about $12.5 \mathrm{~km}$ to the west of Sun Moon Lake in Taiwan (Fig.1) at local time 1:47 a.m., September 21, 1999. Over 13,000 houses collapsed or were seriously damaged. Property damage exceeded NT $\$ 300$ billion, and there were over 2,400 deaths. The Chi-Chi event was the most catastrophic earthquake Taiwan experienced in the 20th century.

The tremor was related to the Chelungpu fault, more than $80 \mathrm{~km}$ long in central western Taiwan. We conducted a geological field investigation (Lin et al. 2000a; Lin et al. 2000b; Lin et al. 2000c; Ouchi et al. 2000) and randomly interviewed locals at the scene from November 29 to December 6, 1999. Major earthquakes might be accompanied by certain precursors or anomalous phenomena as shown in Fig. 2 (Ma et al. 1990). The purpose of the interviews was to preserve non-instrumental records about possible precursory and coseismic information

\footnotetext{
${ }^{1}$ Institute of Applied Geophysics, National Taiwan Ocean University, Keelung, Taiwan, ROC

${ }^{2}$ Research Center for Urban Safety and Security, Kobe University, Kobe 657-8501, Japan

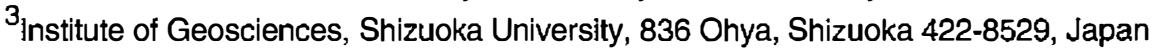

* Corresponding author address: Prof. Allen T. Chen, Institute of Applied Geophysics, National Taiwan Ocean University, \#2 Beining Road, Keelung, 202 Taiwan; E-mail: achen@mail.ntou.edu.tw
} 


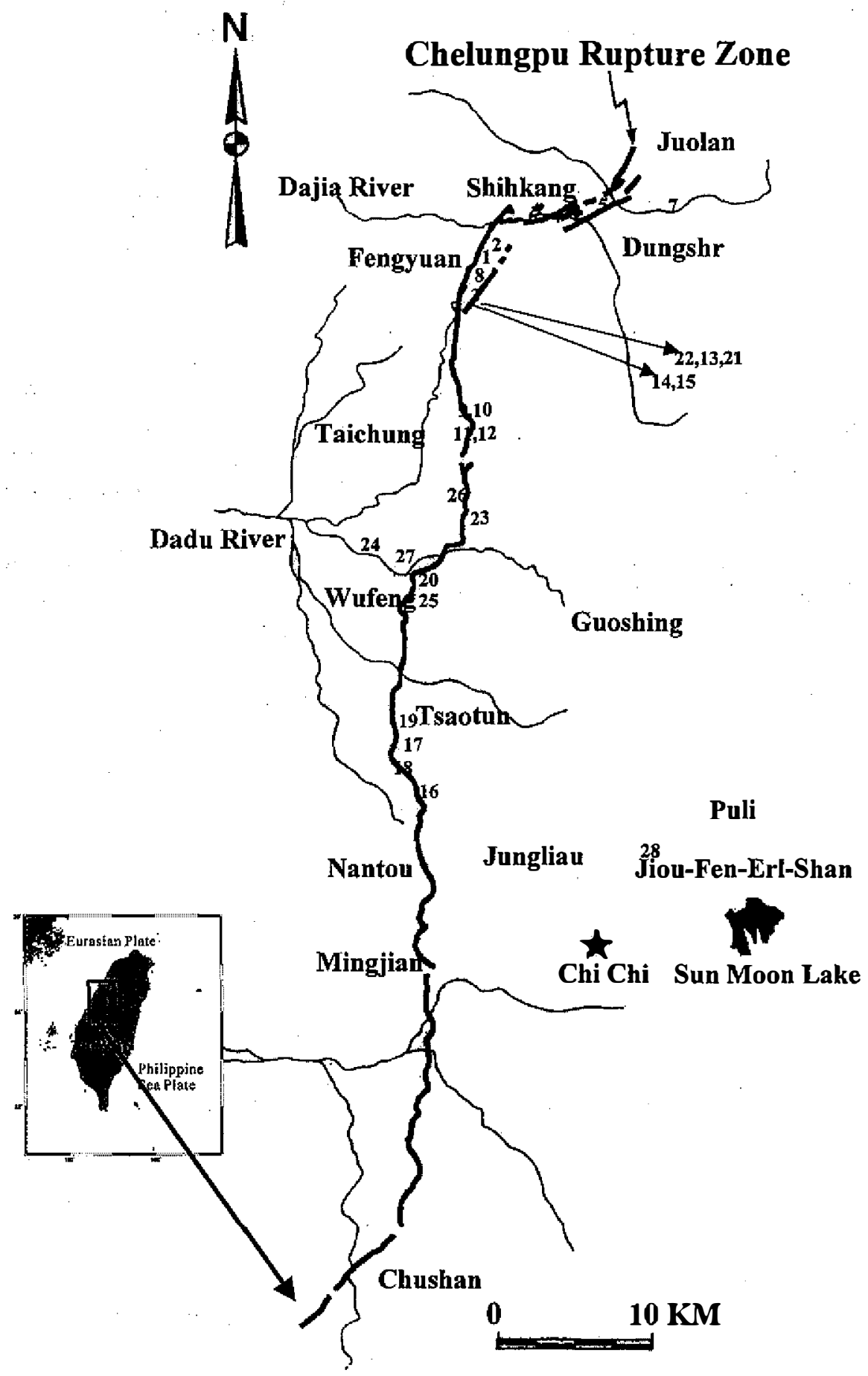

Fig. 1. Tectonic map of the study area. Locations of the main shock and interview sites are labeled with asterisk and numerals. 
associated with the earthquake. As such, the databank may provide some direction about precursory observations and the study of phenomena related to major earthquakes in the future.

\section{DESCRIPTION OF THE INTERVIEWS}

The interviews were conducted every time we had an opportunity to talk with local people
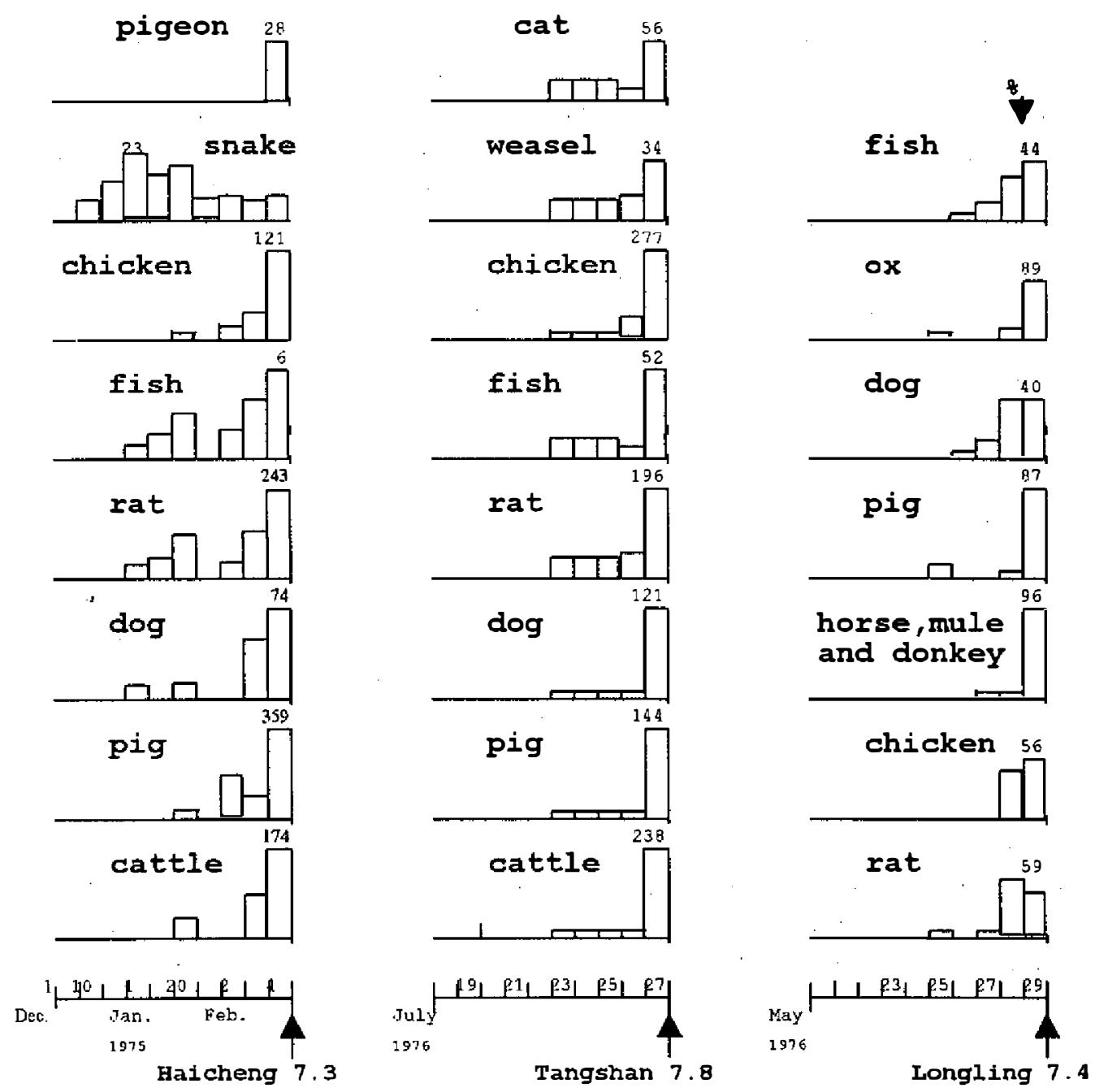

Fig. 2. Animal precursors collected for 3 earthquake events which occurred in China (after Ma et al. 1990). Note: while percentages are used in column diagrams of the Longling event, the frequency of occurrence is used in the cases of the Haicheng and Tangshan events. 
while we were racing the fault zone in our geological field investigation. The survey included the following questions:

(1) Where were you when the earthquake occurred?

(2) Did you perceive any unusual phenomena, such as abnormal animal behavior, lightening, sound, change in the water of wells, etc. and, if so, how long before the earthquake did you observe them?

(3) Which direction of motion of the earthquake did you feel first?

The sites of the interviews conducted are 90 percent the same as the sites of observations reported (Fig. 1); the other 10 percent of the respondents were living in temporary housing provided by the Buddhist Tzu-Chi organization. The results of the interviews are summarized in Fig. 3 and Table 1-3. The locations of reported unusual activity were mainly along the Chelungpu fault zone and in the Jiou-Fen-Erl-Shan region, where a destructive hill slide occurred, destroying a nearby village.

\subsection{Aberrant Animal Behavior}

Ants ( 4 cases)

People reported that ants were highly mobile and building new nests on trees at locations $4,7,21$ and 24. The observed ant activity spread from the northem end to the middle section of the Chelungpu fault. The activity occurred as early as two months prior to the main shock.

Dogs and cats ( 5 cases)

Dogs behaved nervously, barking abnormaly at locations $16,19,20$ and 21 , or were frightened to go to the hill at location 20 within 24 hours before the earthquake. Cats disappeared the day before the earthquake, according to one family interviewed at location 16 .

Earthworms and diplopods (4 cases)

Thousands of earthworms and diplopods reportedly climbed up onto the ground surface earlier than 10 days before the main shock triggered near Nantou town (locations 16,17 ) and Tsaotun town (location 19). Local news reported the same phenomenon in various locations associated with aftershocks and other events (e.g., China Times reports on Oct.26 and 27, 1999).

Fish (2 cases)

Two cases related to an unidentified species of fish were reported: one where fish jumped out of the water in a fish pond at location 17 the day before the earthquake, and the other where fish and shrimp of unknown species migrated downstream from the hill creek in the Jiou-FenErl-Shan region (location 28), where the most serious hill slide and slump occurred more than 


\section{Anomalous Animal Behavior}

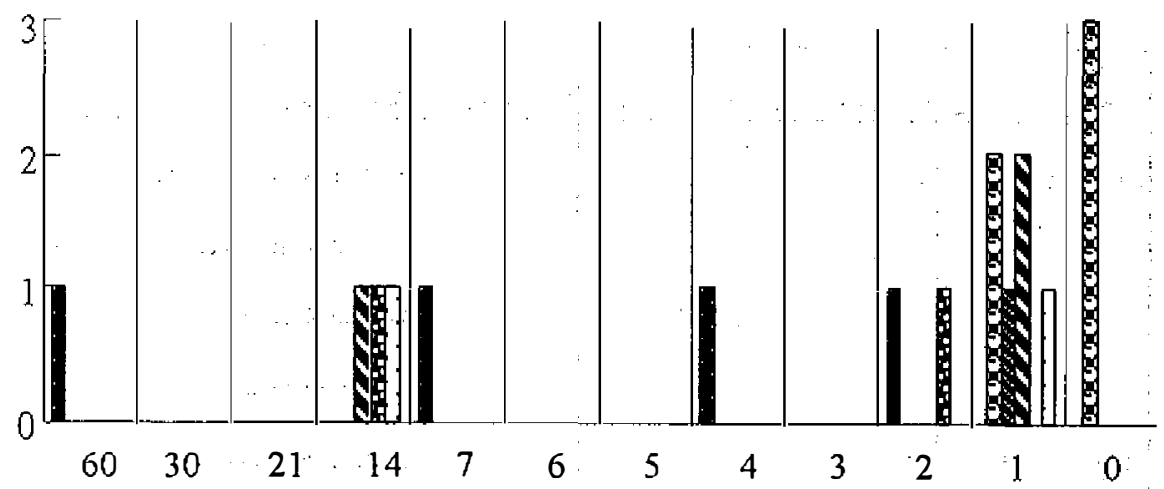

TIME (within days before the earthquake)

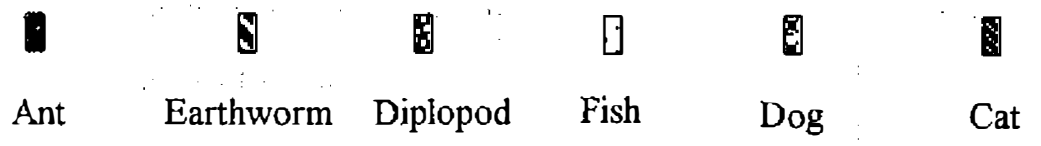

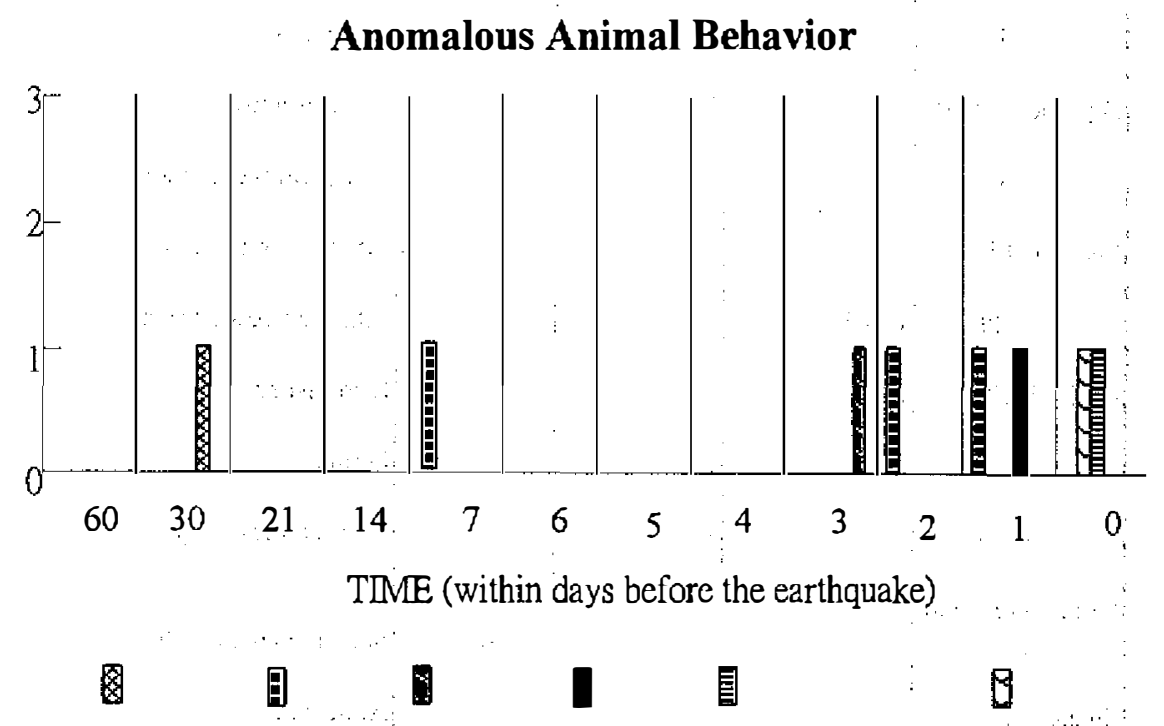

Cicada Bird ., Roach Turtle Snake Palm civet-like animal

Fig. 3. Anomalous animal behavior reported by local residents near the Chelungpu fracture zone. 
Table 1. Reported Anomalous Animal Behavior.

\begin{tabular}{|c|c|c|c|c|c|}
\hline \multicolumn{2}{|c|}{ Items } & \multirow{2}{*}{$\begin{array}{l}\ln \# \text { of weeks } \\
8 \text { to } 10\end{array}$} & In \# of days & In \# of hrs & Description \\
\hline Ant & L. 4 & & & & Built new nest on tree \\
\hline & L. 7 & & 1 & & Moved \& gathered beneath a shoe \\
\hline & L. 21 & & 2 to 3 & & Moved \& gathered \\
\hline & L. 24 & 1 & & & Built new nest on tree \\
\hline Dog & L. 16 & & 1 & & Barked nervously \\
\hline & L. 19 & & & 1 & Barked forcibly \\
\hline & L.20 & & & A few & Cried on hill top \\
\hline & & & 1 & & Refused to go the hill \\
\hline & L. 21 & & & A few & Cried on the roof \\
\hline Cat & L. 16 & & 1 & & Disappeared \\
\hline Earth & worm $\mathrm{L} .17$ & 1 to 2 & 1 & & $\begin{array}{l}\text { Climbed up onto ground surface in } \\
\text { large numbers }\end{array}$ \\
\hline & L. 19 & : & 1 & & Same as above \\
\hline Diplo & pod L.16 & & 1 to 2 & & Same as above \\
\hline & L. 17 & 1 to 2 & & & Many migrated indoors \\
\hline Fish & L.17 & & 1 & & Jumped out of the water \\
\hline & L. 28 & 1 to 2 & & & Migrated downstream \\
\hline Bird & L. 17 & 1 & & & Diminished \\
\hline & L. 20 & 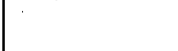 & 2 & & Disappeared \\
\hline & L. 24 & & 1 & & Chirped nervously \\
\hline Palm & $\begin{array}{l}\text { civet- like } \\
\text { L.1 }\end{array}$ & & . & A few & Screamed nervously \\
\hline Snake & L. 12 & & & 2 & Appeared \\
\hline Turtle & L. 16 & & 1 & & Appeared \\
\hline Cicad & a L.17 & 4 to 6 & & & Ceased croaking \\
\hline Roact & L.24 & & 3 & & Appeared \\
\hline
\end{tabular}


Table 2. Reported Non-animal Associated Phenomena.

\begin{tabular}{|c|c|c|c|}
\hline Items & In \# of days & In \# of hrs & Description \\
\hline $\begin{array}{l}\text { Wind L.7,9- } \\
15,17,18,20- \\
22,24-27\end{array}$ & $\begin{array}{l}\text { Generally } \\
1 \text { day }\end{array}$ & & Strong \\
\hline $\begin{array}{l}\text { Skylight } \\
\text { L.3,8,11,13- } \\
15,19,24\end{array}$ & & a few & Red or colorful sky seen \\
\hline $\begin{array}{l}\text { Seismic light } \\
\text { L. } 1\end{array}$ & & coseismic & Emission of green light \\
\hline $\begin{array}{l}\text { Sound } \\
\text { L. } 1,2,4,20,21 \text {, } \\
24,25\end{array}$ & & coseismic & $\begin{array}{l}\text { Distant thunder/ Passing } \\
\text { truck- like sounds }\end{array}$ \\
\hline Smell L.22 & & coseismic & Gaseous odors \\
\hline Initial motion & & coseismic & $\begin{array}{l}88 \% \text { for lateral and } 12 \% \\
\text { for vertical first }\end{array}$ \\
\hline
\end{tabular}

ten days before the earthquake.

Birds ( 3 cases)

Bird-watchers reported fewer birds than usual at locations 17 and 20 as early as one week before the main shock. People at location 24 reported that the mavis species chirped nervously the day before the main shock.

Other animals (single case)

A palm civet-like animal screamed nervously in an agitated way on the eve of the earthquake at location 1. A black snake at location 12 (snake was never found here before) appeared two hours before the main shock, while a turtle from an unknown place appeared the day before the earthquake at location 16. Cicadas ceased croaking as early as August, respondents at location 17 reported. Roaches which had never been seen before in a house at location 24 appeared three days before the main shock. 
Table 3. Reported Shock Aftereffects.

\begin{tabular}{|lr|l|l|}
\hline tems & & After main shock & Description \\
\hline Well & $\begin{array}{r}\text { water } \\
\text { L.1 }\end{array}$ & lasted a few days & Became muddy \\
& L.4,21 & a few days later & Became dry \\
& L.13 & unspecified & Water level dropped 3 m. \\
Light & L.13 & unspecified & Skin darkened under sunlight \\
& L.1 & within a few days & Green light-exposed side of \\
& & papayas turned red or yellow \\
Plant & L.13 & several days later & $\begin{array}{l}\text { Bamboo and longan rees } \\
\text { withered }\end{array}$ \\
& L.16 & a few weeks later & $\begin{array}{l}\text { Boil rice flowers bloomed } \\
\text { earlier and grew lower }\end{array}$ \\
\hline
\end{tabular}

\subsection{Non-animal associated phenomena}

Wind (17 cases)

Reports of unusually strong wind on the eve of the earthquake were made in 17 locations along the fault zone.

Luminescence ( 9 cases)

Red and colorful luminescence in the sky was observed at nine locations the night before the main shock. The emission of green light from the fault front underground was observed during the main shock at location 1 .

Sound ( 7 cases)

Accompanying the main shock, people at seven locations (1, 2, 4, 20, 21,24 and 25) reported sound of a low frequency described as the rumbling of distant thunder, pounding on the ground, or as the passing of an 18-wheeler truck. 
Smell (1 case)

Unusual gaseous odors were reported during the earthquake at location 22 .

Initial ground motion ( 25 cases)

Twenty-two out of the entire sample (or $88 \%$ ) reported initial lateral motion followed by vertical motion as the main shock occurred.

\subsection{After effects}

Well water ( 4 cases)

Water in local wells became muddy for a few days following the earthquake at locations 1,4 and 13. Wells at locations 4 and 21 dried up after the main shock, while the water level of one well was about 3 meters lower than usual at location 13.

Light effect ( 2 cases)

The skins of local people were darkened after they were exposed to sunlight following the main shock, according to respondents at location 13. Those who reported the phenomenon emphasized that their skins had never been so dark before, no matter how long they had been exposed to sunlight.

In the days following the event, papayas that faced the green light that was emitted at location 1 turned yellow or red, whereas the other side remained green.

Plants

People at location 13 reported that bamboo and longan trees withered by the fault scarp after the earthquake, while boil rice flowers bloomed earlier but grew shorter than normal at location 16 .

\section{DISCUSSION}

It is difficult to clearly define the true precursors. Some detailed experiments are surely required in order to fully understand the mechanisms causing the precursory phenomena. A comprehensive overview of the mechanisms for the precursors based on aberrant animal behavior is beyond the scope of this report. It is, however, worth noting the results of the interviews presented here.

Many animal species may be equipped with some special ability to detect environmental changes that human beings are insensitive to. Even ants have been described as being susceptible to earthquakes (Lomintz 1994). Similarly, other birds and mammals, such as pigeons, cats, snakes, weasels, chickens, fish, oxen, rats, dogs, pigs, horses, rabbits, and frogs behaved anomalously before the 1975 Haicheng, 1976 Tangshan or Longling earthquakes (Fig. 2) (Deng 
et al. 1981; Lomintz 1994). Japanese people traditionally believe that catfish have the ability to sense earthquakes before they occur (Lomintz 1994).

Even so, animal behavior should be considered only a possible sign of environmental change, not a sufficiently proven indicator of imminent earthquakes. Combined observations and careful screening of aberrant behavior in animals and birds can provide true precursors of earthquakes with a higher level of confidence. The aberrant behavior in ants, dogs, cats, earthworms, diplopods, fish, shrimps, birds, snakes, and turtles, as reported above (Fig. 3), could collectively serve as an "alarm" of an impending earthquake.

The successful warnings issued before the Haicheng earthquake are impressive, indeed. The initial precursors could be traced back almost two months before the earthquake. The frequency of aberrant animal behavior was noticeable and sharply increased on the day before the earthquake. It seems to provide pretty solid evidence for such earthquake wamings. However, this is not the case in the Chi-Chi earthquake since most available data we collected were only for single cases of animal behavior. The isolated aberrant behavior of ants which occurred as early as $8-10$ weeks before the event is hardly solid evidence which can be related to the Chi-Chi earthquake. Apparently, long-term systematic observations are necessary in facilitating the animal warning system as earthquake precursors.

Among non-animal precursors, sky luminescence was observed before previous earthquakes, such as the 1965 Matsushiro swarm in Japan, the 1973 Veracruz event in Mexico and the 1977 destructive Vrancea event in Romania (Lomintz 1994). Thunder-like sounds, changes in the level of ground water, and an increase in radon were reported as either coseismic phenomena or precursors of the 1975 Haicheng earthquake and the 1976 Sonpan earthquake (Deng et al: 1981; Teng and Henyey 1981). Associated with the Chi-Chi earthquake, however, were strong winds, skylight, thunder-like sounds and unusual gaseous odors that occurred before the main shock. Collectively, these signals might equally serve as indications of an imminent earthquake as those based on aberrant animal behavior.

In addition to the precursors, there were coseismic and after shock phenomena, including the first motion, water levels, light effects and withered plants. We determined the first motion must have been lateral and was followed by vertical motion for two reasons. First, $88 \%$ of the data we collected reported lateral motion and, second, the earthquake was so shallow (about $8 \mathrm{~km}$ ) that the horizontal component of the motion would have been predominant to neardistant observers. The dry wells, lower water levels and withered plants might have been related to the drop in the water table from the uplifting of the crustal structure on the hanging wall of the thrust fault. The muddy well water might have been due to the clay upwelling from underground or liquefaction, a phenomena we observed on the surface during our geological investigation at location 11 . The unusual papaya colors and the early blooming boil rice flowers might be explained by some sort of energy release during the earthquake which was absorbed by the plants causing them to mature earlier even though they had not completely grown yet.

We therefore suggest that a watch network monitoring abnormal animal behavior should be considered and administered by a proper agency under the Ministry of Interior or the National Science Council because such a job would be very difficult for individuals or a group of people due to limited resources. The agency would be responsible for collection, analysis, 
research and judgment of data, and for issuing a warning if an earthquake is considered imminent.

\section{CONCLUSIONS}

Possible precursors of earthquakes collected through regular systematic observation can provide a waming about impending shocks. But it must be kept in mind that a precursor-based warning system can not determine the precise location and magnitude of a shock. Nonetheless such a system of alert could greatly reduce the casualty rate and is worth establishing until such time that full prediction becomes possible.

Precursors of earthquakes may include aberrant animal behavior and non-animal related phenomena. It is essential to differentiate between true precursors and false ones in order to issue valid cautionary procedures for major earthquakes. Phenomena associated with the after-effects of shocks, however, may have all been related to released energy or upward crustal movement during the Chi-Chi earthquake.

Acknowledgements The authors would like to thank each person who spent time being interviewed with us during our field investigations. This work was supported by grant NSC892921-M-019-004-EAF and also partially by the Research Center for Urban Safety and Security, Kobe University and the Faculty of Earth and Planetary Sciences, Kobe University.

\section{REFERENCES}

Deng, Q., J. Pu, L. M. Jones, and P. Molnar, 1981: A preliminary analysis of reported changes in ground water and anomalous animal behavior before the 4 February, 1975 Haicheng earthquake, in Earthquake prediction. In: D. Simpson and P. Richards (Eds.), Maurice Ewing Series, vol 4., Am. Geophys. Union, Washington, DC, 543-565.

Lin, A., T. Ouchi, T., A. Chen, and T. Maruyama, 2000a: Co-seismic displacements, folding structures and paleoseismic events along the Chelungpu surface rupture zone occurred during the 1999 Chi-Chi (Taiwan) earthquake. Proceedings of the Hokudan international symposium and school on active faulting (Awaji Island, Hyogo Prefecture, Japan), 583-584.

Lin, A., T. Ouchi, T., A. Chen, and T. Maruyama, 2000b: Co-seismic displacements, folding and shortening structures along the Chelungpu surface rupture zone occurred during the 1999 Chi-Chi (Taiwan) earthquake. Tectonophysics, (Submitted).

Lin, A., T. Ouchi, T., A. Chen, and T. Maruyama, 2000c: Historic seismic-event produced by a slip on the Chelungpu fault zone, Taiwan. Bull. Seismo. Soc. Am., (Submitted).

Lomintz, C., 1994: Fundamentals of earthquake prediction. John Wiley \& Sons, Inc., New York, $326 \mathrm{pp}$.

Ma, Z., Z. Fu, Y. Zhang, C. Wang, G. Zhang, and D. Liu (Eds.), 1990: Earthquake prediction. Seismological Press/Springer-Verlag, Beijing/Heidelberg, $332 \mathrm{pp}$.

Ouchi, T., A. Lin, A. Chen, and T. Maruyama, 2000: The 1999 Chi-Chi (Taiwan) earthquake- 
earthquake fault and strong motions. In the Combined Reports of the 921 Chi-Chi (Taiwan) Earthquake Investigation, Kobe University, 43-54.

Teng, T., and T. L. Henyey, 1981: The detection of nonearthquakes, in Earthquake prediction. In: D. Simpson and P. Richards (Eds.), Maurice Ewing Series, vol 4., AGU, Washington, DC. 